\title{
PENGEMBANGAN INDUSTRI PERIKANAN TANGKAP DI PERAIRAN BARAT SUMATERA BERBASIS EKONOMI BIRU (Industrial Development in Fisheries at West Sumatera Padang Waters Based on Blue Economy)
}

\author{
Dini Purbani ${ }^{1 *}$, Abdullah Aman Damai ${ }^{2}$, Yulius $^{1}$, Eva Mustikasari $^{1}$, \\ Hadiwijaya Lesmana Salim ${ }^{1}$ dan Aida Heriati ${ }^{1}$ \\ ${ }^{1}$ Pusat Penelitian dan Pengembangan Sumberdaya Laut dan Pesisir, Balitbang Kelautan dan \\ Perikanan-KKP, Jl Pasir Putih 1, Ancol Timur, Jakarta 14430. \\ ${ }^{2}$ Fakultas Pertanian Universitas Lampung Jl. Prof. Dr. Sumantri No. 1 Bandar Lampung, 35145.
}

*Penulis korespondensi. Tel: 08128355048. Email: diniwilnon@gmail.com.

Diterima: 12 Januari 2016

Disetujui: 12 Mei 2016

\begin{abstract}
Abstrak
Sistem analisis prospektif partisipatif bertujuan untuk menentukan variabel kunci pengembangan industri perikanan tangkap berkelanjutan sesuai konsep ekonomi biru. Penelitian dilakukan di TPI Muaro Kota Padang dan PPS Bungus Teluk Kabung Padang, Provinsi Sumatera Barat. Pengelolaan perikanan tangkap di PPS Bungus dan TPI Muaro Kota Padang masih belum memanfaatkan limbah hasil pengolahan dan sistem pengelolaannya belum berbasis ekonomi biru sehingga perlu dilakukan kajian kebijakan dalam pengelolaan. Pendekatan yang dilakukan dalam menentukan kebijakan pengelolaan menggunakan analisis Prospektif partisipatif dengan melakukan konsinyasi dengan para stakeholder yang terkait seperti Dinas Kelautan dan Perikanan Provinsi Sumatera Barat, Dinas Kelautan dan Perikanan Kota Padang, Kepala Bagian Operasional PPS Bungus, BKPM Sumatera Barat, PT Dempo dan nelayan PPS Bungus dan TPI Kota Muaro Kota Padang. Hasil konsensus diperoleh 4 variabel utama empat variabel penyusun kebijakan yaitu ramah lingkungan, kebersamaan gotong royong, peningkatan industri dan tidak menyisakan limbah.
\end{abstract}

Kata kunci: analisis prospektif partisipatif, cakalang, ekonomi biru, industri perikanan, limbah perikanan tuna, tongkol.

\begin{abstract}
The aim of participatory prospective analysis is to determine key variables in the development of sustainable fishing industry according to the blue economy concept. The study was conducted at TPI Muaro Padang City and PPS Bungus Kabung Bay Padang, West Sumatra Province. Further study is required in its management policy, as the fishery management in PPS Bungus and TPI Muaro Padang has not applied the blue economy approach yet, thus its waste utilization. The participatory prospective analyses approach was applied in determining the management policy by organizing consignment by relevant stakeholders such as Department of Marine and Fisheries of West Sumatra Province, Department of Marine and Fisheries of Padang City, Chief Operating of PPS Bungus , BKPM West Sumatra, PT Dempo and fishermen of PPS Bungus and TPI Muaro Padang City. This resulted in four main variables of policy making namely environmentally friendly, mutual cooperation in togetherness, industrial increase and zero waste.
\end{abstract}

Keywords: participatory prospective analysis, skipjack, blue economy, fisheries industry tuna, fisheries waste, mackerel tuna.

\section{PENDAHULUAN}

Perairan Sumatera Barat memiliki potensi perikanan tangkap yang besar. Berdasarkan data Padang dalam angka 2012 (Anonim, 2012 ${ }^{\mathrm{a}}$ ) data hasil tangkapan ikan tuna $3.996,3$ ton, tongkol $3.142,2$ ton dan cakalang $5.434,8$ ton. Tuna yang terbanyak jenis adalah tuna ekor kuning/madidihang (yellowfin/Thunnus albacares) dan tuna matabesar (bigeye/Thunnus obesus). Tongkol yang dominan tongkol krai dan tongkol komo/kawakawa (Euthynus affinis).
Dari pengamatan lapangan, penulis melakukan wawancara di Pelabuhan TPI Muaro Kota Padang dengan nahkoda dan juga sebagai nelayan dari Kapal Pristi berfungsi sebagai kapal pancing tonda. Hasil wawancara nelayan menangkap ikan tuna pada bulan Desember 2013 secara tradisional menggunakan kapal berbobot $8 \mathrm{GT}$, ruaya (operasi penangkapan) di sekitar pesisir dengan hari layar 1 minggu dengan hasil tangkapan sebagian besar anakan tuna (juvenile) jenis tuna sirip kuning dan tuna matabesar/bigeye tuna. Panjang badan anakan tuna jenis tuna madidihang anakan yang tertangkap mempunyai kisaran ukuran panjang 29-65 cm 
panjang tengah dengan modus pada nilai tengah 38 $\mathrm{cm}$.

Kondisi tangkapan ikan di PPS Bungus berdasarkan data statistik tahun 2012 jumlah tangkapan tuna mata besar/bigeye tuna 632,12 ton, tuna sirip kuning/madidihang/yellowfin tuna 580,03 ton, cakalang (skipjack tuna) 428,30 ton. Hasil tangkapan tongkol komo (eastern little tuna) 43,90 ton, tongkol krai (frigate tuna) 70,75 ton dan tongkol abu-abu (longtail tuna) 10,78 ton. PPS Bungus merupakan tempat pendaratan kapal dengan bobot 51-100 GT, tangkapan ikan tuna, tongkol dan cakalang menggunakan rawai tuna (tuna long line), pukat cincin (purse seine) dan pancing tonda (troll line) dengan ruaya sampai ke Samudera Indonesia termasuk dalam wilayah pengelolaan perikanan WPP 572 (Anonim, 2011) sehingga hasil tangkapan tuna berat di atas $50 \mathrm{~kg}$ (Anonim, 2012 ${ }^{\mathrm{b}}$ ).

Menurut teori produksi, ada 4 tahapan produksi sumberdaya alam dilihat dari jumlah penggunaan inputnya (Anderson, 1986; Susilowati, 2006). Tahap I adalah produksi yang dapat mencapai keuntungan ekonomi (profit) yang maksimum MEY, tahap II, produksi yangdapat mencapai jumlah produksi fisik yang maksimum MSY, tahap III, produksi yang tidak memperoleh untung atau rugi (break even point atau openacsess), tahap IV adalah produksi yang merugi.

Dalam Rencana Pembangunan Jangka Menengah Daerah (RPJMD) Provinsi Sumatera Barat tahun 2006-2010 memiliki potensi ikan pelagis besar (tuna, cakalang, tongkol dan tenggiri) yang banyak terpusat di perairan antara Kota Padang dan Kabupaten Kepulauan Mentawai. Untuk di sebelah barat Kepulauan Mentawai, yang dapat dilakukan dengan penangkapan secara berkelanjutan dengan produksi maksimum sebesar 34.190 ton/tahun, dengan tingkat produksi penangkapan lestari sebesar 50\% ( Anonim, 2008).

Berkaitan dengan hal tersebut dalam penangkapan ikan perlu memperhatikan UU 31 tahun 2004 Bab IV pasal 6 tentang Pengelolaan Perikanan ayat 1 disampaikan bahwa Pengelolaan perikanan dalam (WPP) Republik Indonesia dilakukan untuk tercapainya manfaat yang optimal dan berkelanjutan, serta terjaminnya kualitas sumberdaya ikan. Berdasarkan Kep Men no 45/Men/2011 di Lampiran 2 dapat diketahui jenis ikan apa saja yang masih bisa ditangkap antara lain cakalang dalam kondisi moderate, sedangkan jenis Mata Besar sudah over exploited dan Madidihang dalam keadaan fully exploited. Jenis Tuna Mata Besar sudah over exploited dapat diartikan Tuna Mata Besar pemanfaatan laut secara berlebihan namun tidak diimbangi oleh pembudidayaan atau regenerasi. Jenis Tuna Albakora masih dapat ditangkap karena dalam kondisi layak untuk ditangkap. Dengan diketahui kondisi perikanan pelagis besar di perairan Barat Sumatera yang dapat ditangkap untuk sementara adalah cakalang dan albakora.

Hasil tangkapan ikan di TPI Muaro Kota Padang adalah anakan tuna yang dapat mempengaruhi pertumbuhan dan perkembangbiakan ikan sehingga menyebabkan penurunan sumberdaya perikanan (Gjertsen, H., Hall, M., dan Squires, D., 2010). Oleh karena itu dibutuhkan suatu pendekatan dalam pengelolaan perikanan, termasuk perikanan tuna yang mempertimbangkan keberlanjutan sumberdaya perikanan. Analisis prospektif partisipatif, merupakan pendekatan yang mengedepankan proses partisipatif dan mampu memberikan kesepakatan (konsensus) antar-stakeholder (Godet dan Roubelat 1996; Bourgeois dan Jesus 2004; Gray dan Hatchard. 2008; Godet 2010; Human dan Davies, 2010). Dengan demikian berbagai kepentingan stakeholder dapat dijembatani dalam pengembangan industri perikanan tangkap yang berkelanjutan, sesuai konsep ekonomi biru.

Ekonomi biru adalah sistem ekonomi yang didasarkan pada prinsip-prinsip pengelolaan sumber daya alam secara berkelanjutan dan didukung oleh sistem produksi efisien dan bersih tanpa merusak lingkungan demi kemakmuran umat manusia masa kini dan masa mendatang. Ekonomi biru mempunyai tiga kepentingan yakni pertumbuhan ekonomi, kesejahteraan masyarakat, dan penyehatan lingkungan. Ekonomi biru dapat dikatakan sebagai pengembangan ekonomi yang mengandalkan sumberdaya kelautan yang secara masif dikaitkan dengan manajemen kesinambungan dan pelestarian aset (Gunter, 2010).

Berkaitan dengan hal tersebut maka perlu dilakukan penelitian yang menerapkan Analisis Prospektif Partisipatif, untuk pengembangan industri perikanan berkelanjutan, sesuai dengan konsep Ekonomi Biru Berbasis Perikanan Pelagis Besar di Perairan Barat Sumatera. Dalam penelitian ini ingin diketahui variabel kunci dalam pengembangan industri perikanan yang sesuai dengan kebijakan ekonomi biru.

\section{METODE PENELITIAN}

Lokasi penelitian di sekitar perairan Barat Sumatera (Gambar 1). Dalam penelitian ini dilakukan tatap muka dengan para nelayan di Muaro Kota Padang dan di PPS Bungus Teluk Kabung pada tanggal 18 - 22 Maret 2013 agar dapat mengetahui jumlah tangkapan tuna, tongkol dan cakalang di kedua lokasi pendaratan ikan. Selanjutnya tanggal 26 Mei hingga 1 Juli 2013 dan tanggal 15-18 Juli 
2013 dilakukan analisis prospektif partisipatif yang digunakan dalam pengambilan keputusan.

Analisis prospektif partisipatif dirancang untuk mencari dan mengantisipasi perubahan dengan para ahli dan stakeholder. Hasil dari analisis mengeluarkan informasi yang cepat yang dapat digunakan kepada sesama peserta sehingga dapat diperoleh kebijakan dalam pembangunan. Jumlah peserta yang hadir 15 orang meliputi nelayan Muara Kota Padang, para pengambil keputusan dari pemerintah dan swasta seperti Dinas Kelautan dan Perikanan Kota Padang, Provinsi Sumatera Barat, PPS Bungus berada di bawah Direktorat Pelabuhan Perikanan Ditjen Perikanan Tangkap Kementerian Kelautan dan Perikanan dan Badan Koordinasi Penanaman Modal (BKPM) Provinsi Sumatera Barat. Peserta pihak swasta adalah PT Dempo yang bergerak dibidang eksportir ikan tuna segar ke Jepang dan eksportir olahan tuna ke Florida, Amerika Serikat. Tahapan analisis ditampilkan pada Tabel 1. Jenis data yang digunakan dalam analisis ini sesuai dengan konsep ekonomi biru yaitu inovasi dengan meminimalisasi limbah, investasi terbatas, kesempatan kerja, kewirausahaan dan modal sosial.

\section{HASIL DAN PEMBAHASAN}

\section{Analisis Prospektif Partisipatif untuk Penentuan Variabel Kunci}

Dalam pertemuan tersebut, pakar atau peserta diminta untuk mengidentifikasi variabel kunci yang dianggap paling berpengaruh terhadap kebijakan ekonomi biru perikanan pelagis besar di perairan barat Sumatera. Berdasarkan parameter tersebut maka dilakukan identifikasi masalah dengan membagi menjadi 6 domain dengan sub domainnya sehingga variabel yang perlu diamati adalah 25 variabel (Tabel 2).

Variabel yang terdapat Tabel 2 diidentifikasikan menjadi 14 variabel kunci beserta definisinya (Tabel 3). Variabel yang terdapat di Tabel 3 merupakan hasil diskusi dan konsensus yang dicapai oleh peserta. Dalam hal ini belum diketahui variabel yang paling menentukan dalam penyusunan model kebijakan ekonomi biru. Pengaruh antar variabel juga belum dapat digambarkan, sehingga semua variabel memiliki kepentingan dan kekuatan yang sama terhadap sistem. Di sisi lain, perlu diketahui perbedaan tingkat pengaruh variabel untuk menentukan variabel yang perlu diintervensi sebagai titik masuk (entry point) bagi perencanaan yang efektif (Godet dan Roubelat, 1996; Bourgeois dan Jesus, 2004; Gray dan Hatchard, 2008; Godet, 2010; Damai, 2012).

\section{Analisis Pengaruh Antar-Variabel Kunci}

Berdasarkan 14 variabel pada Tabel 3, kemudian peserta kembali berdiskusi dan secara konsensus memberikan skor pada pengaruh silang antar variabel, yang dianalisis secara matriks dengan bantuan perangkat lunak Excel (Bourgeois dan

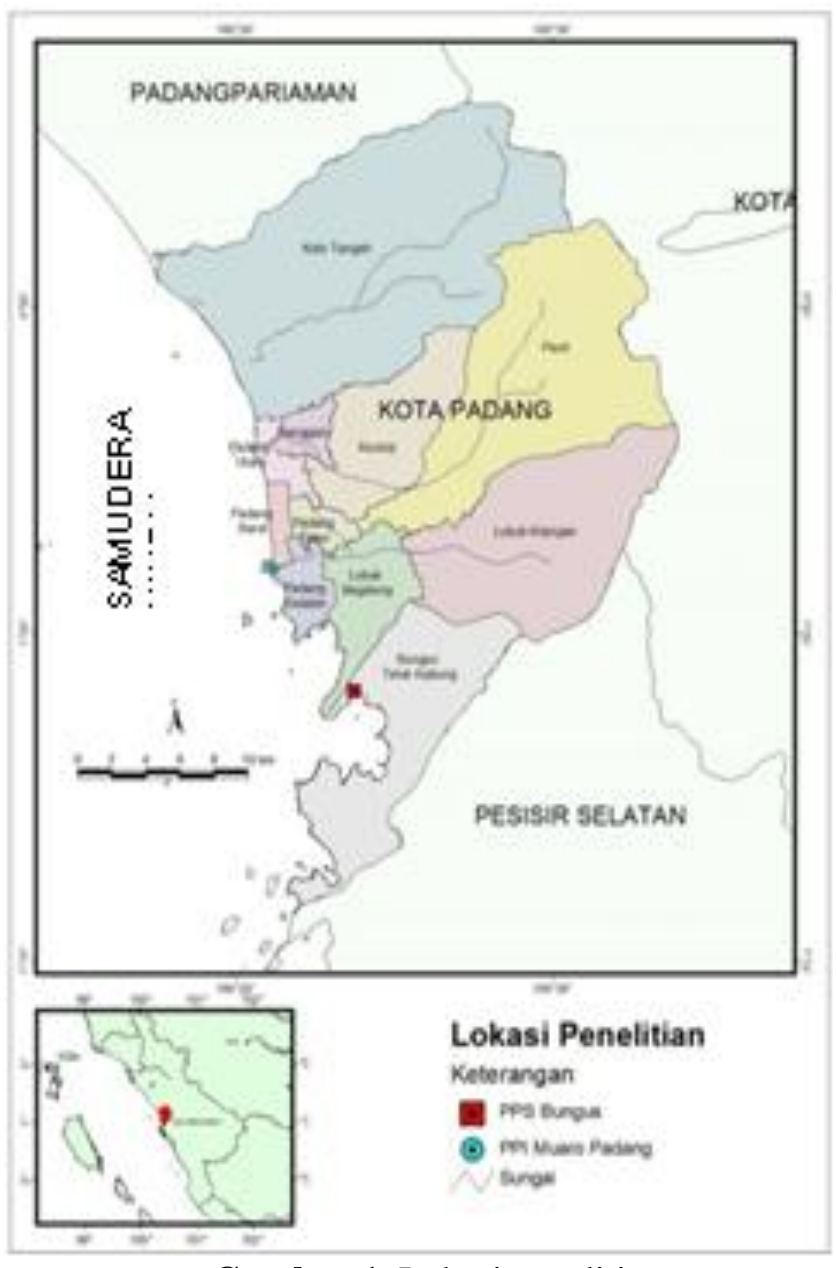

Gambar 1. Lokasi penelitian.

Tabel 1.Tahapan analisis prospektif partisipatif.

\begin{tabular}{cll}
\hline No & \multicolumn{1}{c}{ Tahapan } & \multicolumn{1}{c}{ Pendekatan } \\
\hline 1 & Penentuan/definisi sistem & Persiapan awal dan diskusikelompok \\
2 & Identifikasi variabel & Curah pendapat \\
3 & Definisi variabel kunci & Diskusi kelompok terstruktur \\
4 & Analisis pengaruh antar variabel & Analisis struktural dan kerja kelompok \\
5 & Interpretasi dari pengaruh dan ketergantungan antar & Diskusi kelompok yangdidukung dengan \\
& variabel & grafik dantabel hasil analisis \\
6 & Pendefinisian kondisi variabel di masa datang. & Analisis morfologis dandiskusi kelompok \\
7 & Pembangunan skenario & Curah pendapat \\
8 & Penyusunan implikasi strategis dan aksi antisipatif & Diskusi terstruktur \\
\hline
\end{tabular}


Tabel 2.Variabel pengaruh yang diidentifikasi oleh peserta.

\begin{tabular}{llc}
\hline No & \multicolumn{1}{c}{ Variabel } & Domain \\
\hline 1 & Kebersamaan gotong royong & \\
2 & Hukum adat & \\
3 & Pemberdayaan masyarakat pesisir & \\
4 & Perilaku nelayan dalam menangkap ikan (budaya) & Inovasi \\
5 & Karakter nelayan & \\
6 & Sarana penangkapan ikan di TPI Muaro & \\
7 & Sarana penangkapan ikan di PPS Bungus & \\
8 & Sarana pelabuhan ikan di TPI Muaro & Investasi terbatas \\
9 & Sarana pelabuhan ikan di PPS Bungus & \\
10 & Teknologi penginderaan jauh untuk perikanan tangkap & \\
11 & Sumber modal nelayan & Kesempatan kerja \\
12 & Jasa angkutan & \\
13 & Sarana penangkapan ikan & \\
14 & Sarana pelabuhan & \\
15 & Nakhoda kapal & \\
16 & Anak Buah Kapal (ABK) & \\
17 & Nelayan & \\
18 & Pengecek kualitas Tuna & \\
19 & Buruh pabrik & \\
20 & Limbah dari suatu produk akan menjadi bahan material bagi & Tidak menyisakan limbah \\
& produk yang lain & \\
21 & Tidak menyisakan limbah & Kewirausahaan \\
22 & Ramah lingkungan & \\
23 & Peningkatan industri & \\
24 & Inovasi umpan & \\
25 & Sumber daya manusia & \\
& &
\end{tabular}

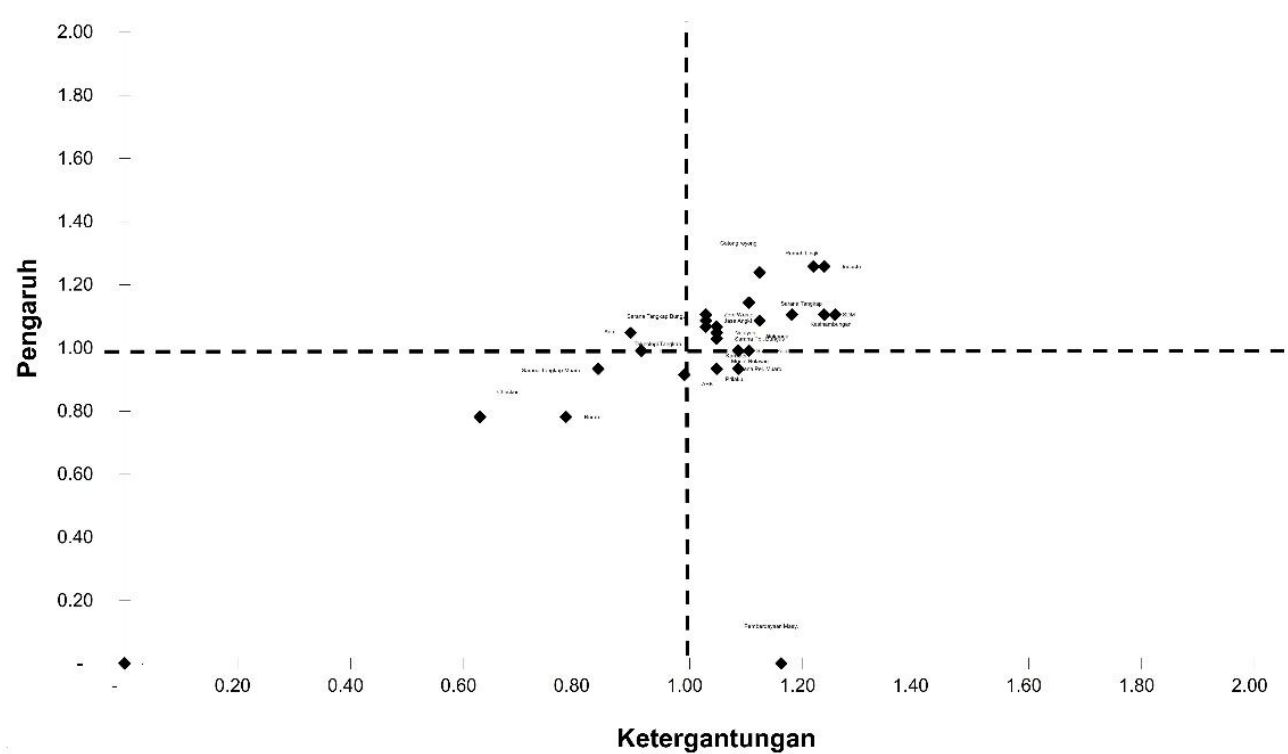

Gambar 2. Hasil analisis pengaruh langsung antar variabel.

Secara praktis, analisis pengaruh langsung terdiri dari valuasi pengaruh langsung suatu variabel terhadap variabel lainnya, dengan menggunakan skala dari " $0=$ tidak ada pengaruh" sampai " $3=$ berpengaruh sangat kuat". Nilai yang telah didiskusikan dan disepakati oleh partisipan, langsung dimasukkan di dalam matriks I/D. Adapun hasil analisis pengaruh antar variabel disajikan dalam bentuk grafik dan tabel, pada Gambar 2.

Masing-masing kuadran berhubungan dengan karakteristik khusus dari variabel. Kuadran I (kiri atas) merupakan wilayah variabel penggerak (driving). Kuadran II (kanan atas) merupakan wilayah variabel kontrol (leverage), yang bercirikan pengaruh dan juga ketergantungan kuat, beberapa variabel dalam kuadran ini dapat juga digolongkan sebagai variabel kuat. Kuadran III (kanan bawah) merupakan wilayah variabel keluaran (output), yang bersifat sangat tergantung dan hanya sedikit pengaruh. Kuadran IV (kiri bawah) merupakan wilayah variabel marjinal (marginal), kelompok ini akan langsung dikeluarkan dari analisis. Selain ke 
Tabel 3. Variabel pengaruh yang diidentifikasi dan didefinisikan oleh partisipan.

\begin{tabular}{|c|c|c|c|}
\hline No & Domain & Variabel & Definisi dan deskripsi \\
\hline 1 & Modal sosial & Kebersamaan gotong royong & $\begin{array}{l}\text { Semua nagari di Sumatera Barat melaksanakan } \\
\text { (Kerapatan Adat Nagari) KAN setiap bulan }\end{array}$ \\
\hline 2 & & Hukum adat & $\begin{array}{l}\text { Penerapan hukum adat dalam pengelolaan dan } \\
\text { pelestarian perikanan tangkap }\end{array}$ \\
\hline 3 & & $\begin{array}{l}\text { Perilaku nelayan dalam } \\
\text { menangkap ikan (budaya) }\end{array}$ & $\begin{array}{l}\text { Pengetahuan nelayan dalam menangkap ikan tuna, } \\
\text { tongkol dan cakalang menggunakan alat pancing } \\
\text { ramah lingkungan (pancing ulur) dan juga } \\
\text { memperhatikan ikan yang ditangkap sesuai atau } \\
\text { layak dengan berat ikan dan usia }\end{array}$ \\
\hline 4 & Inovasi & $\begin{array}{l}\text { Sarana penangkapan ikan di TPI } \\
\text { Muaro }\end{array}$ & $\begin{array}{l}\text { Sarana penangkapan ikan perlu ditingkatkan } \\
\text { melalui bantuan pemda maupun dari kelompok } \\
\text { nelayan }\end{array}$ \\
\hline 5 & & $\begin{array}{l}\text { Sarana penangkapan ikan di PPS } \\
\text { Bungus }\end{array}$ & $\begin{array}{l}\text { Sarana penangkapan ikan perlu ditingkatkan } \\
\text { melalui bantuan pemda maupun dari kelompok } \\
\text { nelayan }\end{array}$ \\
\hline 6 & & $\begin{array}{l}\text { Teknologi penginderaan jauh } \\
\text { untuk perikanan tangkap }\end{array}$ & $\begin{array}{l}\text { Penginderaan jauh dapat membantu perikanan } \\
\text { tangkap dalam penentuan lokasi tangkapan, } \\
\text { musim tangkapan }\end{array}$ \\
\hline 7 & Investasi terbatas & Sumber modal nelayan & Sumber modal nelayan pribadi atau kelompok \\
\hline 8 & & Jasa angkutan & $\begin{array}{l}\text { Armada yang tersedia dapatkah mencukupi untuk } \\
\text { pengangkutan hasil tangkapan }\end{array}$ \\
\hline 9 & Kesempatan kerja & Nakhoda kapal & $\begin{array}{l}\text { Kurangnya minat dan ketrampilan menjadi } \\
\text { nahkoda }\end{array}$ \\
\hline 10 & $\begin{array}{l}\text { Tidak menyisakan } \\
\text { limbah }\end{array}$ & $\begin{array}{l}\text { Limbah dari suatu produk akan } \\
\text { menjadi bahan material bagi } \\
\text { produk yang lain }\end{array}$ & $\begin{array}{l}\text { Proses dalam pengelolaan sentra tuna harus } \\
\text { mempertimbangkan kesinambungan, dimana } \\
\text { keluaran dari suatu proses dapat dijadikan } \\
\text { masukan bagi proses yang lainnya }\end{array}$ \\
\hline 11 & & Tidak menyisakan limbah & $\begin{array}{l}\text { Limbah tuna yang dihasilkan dapat dimanfaatkan } \\
\text { menjadi bahan pakan, tepung ikan ataupun produk } \\
\text { olahan lainnya }\end{array}$ \\
\hline 12 & & Ramah lingkungan & $\begin{array}{l}\text { Proses penangkapan serta industrinya harus } \\
\text { mempertimbangkan lingkungan dimana emisi gas } \\
\text { buang dan polusi lainnya bagi lingkungan harus } \\
\text { dapat dikurangi }\end{array}$ \\
\hline 13 & Kewirausahaan & Peningkatan industri & $\begin{array}{l}\text { Industri atau pelaku usaha yang terlibat dalam } \\
\text { upaya peningkatan pengelolaan dan pemasaran } \\
\text { tuna yang secara legal dikelola oleh indutri swasta } \\
\text { atau pemerintahan yang memikirkan } \\
\text { kesinambungan. }\end{array}$ \\
\hline 14 & & Sumber Daya Manusia (SDM) & $\begin{array}{l}\text { Kapasitas lulusan serta kemampuan menejerial } \\
\text { SDM yang terdidik dan terlatih khusus di bidang } \\
\text { penangkapan sampai pada pengelolaan ikan tuna. }\end{array}$ \\
\hline
\end{tabular}

empat kuadran, juga terdapat area abu-abu di sepanjang sumbu yang memisahkan kudran IV dari kuadran lainnya. Pada area abu-abu mungkin didapati sekelompok variabel, yang peranannya di dalam sistem tidak dapat diidentifikasi secara jelas.

Dari presentasi hasil analisis pengaruh langsung dan tidak langsung (total) yang tertera pada Gambar 2 dapat dipilih 4 variabel yang dapat dikatakan sebagai variabel paling berpengaruh, yaitu ramah lingkungan, kebersamaan gotong royong, peningkatan industri dan tidak menyisakan limbah. Hal ini ditunjang oleh nilai kekuatan global tertimbang masing-masing variabel, dimana 4 variabel tersebut memiliki nilai yang lebih tinggi dari sepuluh variabel lainnya (Tabel 5). Dari hasil analisis tersebut, maka dapat disimpulkan bahwa variabel nomor 1 sampai dengan 4 , terpilih sebagai variabel paling berpengaruh (Godet dan Roubelat, 1996; Bourgeois dan Jesus, 2004).

\section{Pembangunan Skenario}

Pengembangan skenario pada Tabel 6 dilakukan melalui curah pendapat (brainstorming) dan diskusi kelompok secara terstruktur. Dalam forum tersebut, peserta diminta untuk dapat memberikan perkiraan dari kondisi masing-masing variabel penentu pada masa datang. Perkiraan tersebut merupakan opini dan cerminan kebutuhan 
para pemangku kepentingan di masa depan (Godet dan Roubelat, 1996; Bourgeois dan Jesus, 2004; Gray dan Hatchard, 2008; Coates dkk., 2010; Durance dan Godet, 2010). Dari perkiraan mengenai kondisi variabel tersebut di masa datang, dapat disusun skenario yang mungkin terjadi di PPS
Bungus. Hasil curah pendapat peserta dari konsensus digunakan dalam penyusunan skenario pengembangan industri perikanan tangkap di daerah penelitian yang mungkin terjadi, disajikan pada Tabel 7.

Tabel 5. Skor kekuatan variabel global tertimbang.

\begin{tabular}{llc}
\hline No & Variabel & Kekuatan variabel global tertimbang \\
\hline 1 & Ramah lingkungan & 1,2823 \\
2 & Kebersamaan gotong royong & 1,2473 \\
3 & Peningkatan industri & 1,2172 \\
4 & Tidak menyisakan limbah & 1,1560 \\
5 & Nakhoda kapal & 1,0891 \\
6 & Teknologi penginderaan jauh untuk perikanan tangkap & 1,0567 \\
7 & Sarana penangkapan ikan di PPS Bungus & 1,0531 \\
8 & Jasa angkutan & 1,0436 \\
9 & Sarana penangkapan ikan di TPI Muaro & 1,0436 \\
10 & Perilaku nelayan dalam menangkap ikan (budaya) & 1,0253 \\
11 & Limbah dari suatu produk akan menjadi bahan material bagi & 1,0194 \\
& produk yang lain/kesinambungan & \\
12 & Sumber modal nelayan & 1,0159 \\
13 & Sumber Daya Manusia (SDM) & 1,0012 \\
14 & Hukum adat & 0,9451 \\
\hline
\end{tabular}

Sumber : Data primer, 2013.

Tabel 6. Kondisi variabel yang ditetapkan oleh partisipan secara konsensus.

\begin{tabular}{lcccccc}
\hline Variabel & \multicolumn{7}{c}{ Kondisi yang mungkin terjadi } \\
\cline { 2 - 7 } & Kode & 1 & 2 & 3 & 4 & 5 \\
\hline Ramah lingkungan & A & A1 & A2 & A2 & A3 & A4 \\
Kebersamaan gotong royong & B & B1 & B1 & B2 & B2 & B2 \\
Peningkatan industri & C & C1 & C1 & C2 & C2 & C2 \\
Tidak menyisakan limbah & D & D1 & D1 & D2 & D2 & D2 \\
\hline
\end{tabular}

Keterangan : Kondisi $1=$ bertambah buruk; $2=$ tetap seperti sekarang; $3=$ meningkat dengan progres yang terbatas; $4=$ meningkat dengan baik dan $5=$ kondisi ideal. Sumber : Data primer, 2013.

Tabel 7. Skenario pengembangan industri perikanan tangkap berkelanjutan.

\begin{tabular}{|c|c|c|}
\hline Kondisi & Variabel terpilih & Keterangan \\
\hline Bertambah buruk & A1-B1-C1-D1 & $\begin{array}{l}\text { A1:Ramah lingkungan tidak bisa diterapkan, } \\
\text { B1: Gotong royong akan semakin melemah } \\
\text { C1: Industri tetap seperti sekarang } \\
\text { D1 : Zero waste/tidak menyisakan limbah tidak diterapkan }\end{array}$ \\
\hline Tetap seperti sekarang & A2-B1-C1-D1 & $\begin{array}{l}\text { A2 : Ramah lingkungan akan berubah menjadi lebih baik } \\
\text { B1 : Gotong royong akan semakin melemah } \\
\text { C1 : Industri tetap seperti sekarang } \\
\text { D1 : Zero waste/tidak menyisakan limbah tidak diterapkan }\end{array}$ \\
\hline $\begin{array}{l}\text { Meningkat dengan } \\
\text { progres yang terbatas }\end{array}$ & A2-B2-C1-D1 & $\begin{array}{l}\text { A2 : Ramah lingkungan akan berubah menjadi lebih baik } \\
\text { B2 : Gotong royong akan semakin melembaga } \\
\text { C1 : Industri tetap seperti sekarang } \\
\text { D1 : Zero waste/tidak menyisakan limbah tidak diterapkan }\end{array}$ \\
\hline $\begin{array}{l}\text { Meningkat dengan } \\
\text { baik }\end{array}$ & A3-B2-C2-D2 & $\begin{array}{l}\text { A3 : Ramah lingkungan akan lebih meningkat lagi dengan } \\
\text { diikuti dengan penegakan hukum } \\
\text { B2: Gotong royong akan semakin melembaga } \\
\text { C2 : Industri semakin maju dan berkembang } \\
\text { D2: Zero waste/tidak menyisakan limbah tidak diterapkan }\end{array}$ \\
\hline Kondisi ideal & A4-B2-C2-D2 & $\begin{array}{l}\text { A4: Ramah lingkungan akan lebih meningkat lagi dengan } \\
\text { diikuti dengan insentif } \\
\text { B2: Gotong royong akan semakin melembaga } \\
\text { C2 : Industri semakin maju dan berkembang } \\
\text { D2 : Zero waste/tidak menvisakan limbah tidak diterapkan }\end{array}$ \\
\hline
\end{tabular}


Tabel 8. Perubahan perilaku penangkapan ikan di Muaro Kota Padang.

\begin{tabular}{ll}
\hline \multicolumn{1}{c}{ Dilakukan sekarang } & \multicolumn{1}{c}{ Saran perlakuan } \\
\hline Menangkap ikan di sekitar rumpon & $\begin{array}{l}\text { Mengikuti dan mentaati hukum adat nagari dalam } \\
\text { penjagaan di sekitar rumpon } \\
\text { Tangkapan ikan tuna di atas } 50 \mathrm{~kg}\end{array}$ \\
$\begin{array}{l}\text { Ikan yang ditangkap anakan tuna (juvenile) berat di bawah } \\
50 \mathrm{~kg}\end{array}$ & $\begin{array}{l}\text { Palkah perlu diredisain dengan menggunakan air laut } \\
\text { dan palkah berbahan fiber (Idris., 2012) }\end{array}$ \\
$\begin{array}{l}\text { Ikan hasil tangkapan disimpan di palkah ikan yang } \\
\text { tersimpan tertumpuk-tumpuk menyebabkan ikan yang } \\
\text { terletak bagian bawah menjadi busuk }\end{array}$ & $\begin{array}{l}\text { Melakukan pencataan pengambilan ikan }(\log \text { book }) \\
\text { Tidak ada pencatatan pengambilan ikan (log book), } \\
\text { pencatatan dilakukan di darat }\end{array}$ \\
\hline
\end{tabular}

Tabel 9. Perubahan perilaku penangkapan ikan di PPS Bungus.

\begin{tabular}{ll}
\hline \multicolumn{1}{c}{ Dilakukan sekarang } & \multicolumn{1}{c}{ Saran perlakuan } \\
\hline Sirip dan tulang ekor tidak dimanfaatkan & Dapat dibuat tepung ikan sebagai makanan ternak \\
Penangkapan ikan dengan pukat cincin (purse seine) & Menggunakan pancing ulur \\
\hline Sumber : Data primer, 2013.
\end{tabular}

\section{Implikasi Strategis dan Aksi Antisipatif}

Implikasi strategis dan aksi antisipatif yang dapat dirumuskan oleh partisipan adalah mempersiapkan diri untuk menghadapi situasi di masa datang (pro-aktif); yang juga menyiapkan aksi yang bersifat re-aktif. Melalui identifikasi dan perbandingan skenario, maka para pengambil keputusan dan pemangku kepentingan dapat lebih mampu merencanakan masa depan suatu wilayah (Godet dan Roubelat, 1996; Bourgeois dan Jesus, 2004; Gray dan Hatchard, 2008; Coates, dkk., 2010; Durance dan Godet, 2010).

Ekonomi Biru dapat dilihat sebagai tindakan yang bertumpu pada pengembangan ekonomi rakyat secara komprehensif guna mencapai pembangunan nasional secara keseluruhan. Pendekatan pembangunan berbasis ekonomi biru akan bersinergi dengan pelaksanaan triple track strategy, yaitu program pro-poor (pengentasan kemiskinan), progrowth (pertumbuhan), pro-job (penyerapan tenaga kerja) dan pro-environtment (melestarikan lingkungan).

Analisis prospektif partisipatif menghasilkan empat variabel utama yaitu ramah lingkungan, kebersamaan gotong royong, peningkatan industri dan tidak menyisakan limbah. Pengaplikasian ke empat variabel model kebijakan perlu diterapkan di TPI Muaro Kota Padang dan PPS Bungus tertera pada Tabel 8 dan 9.

\section{KESIMPULAN}

Penangkapan ikan tuna, tongkol dan cakalang di Muaro Kota Padang berbeda dengan di PPS Bungus. Muaro Kota Padang para nelayan menggunakan kapal pancing tonda. Penangkapan dilakukan di sekitar rumpon dengan hasil tangkapan anakan tuna berat di bawah $50 \mathrm{~kg}$. Jenis ikan tuna yang diperoleh adalah jenis tuna sirip kuning/madidihang dan tuna matabesar/bigeye tuna. Hasil tangkapan disimpan dalam palkah yang dapat menyebabkan ikan tuna di lapisan paling bawah menjadi busuk. Perlakuan yang demikian perlu diubah dengan meredesain palkah. Untuk mendapatkan tangkapan tuna di atas $50 \mathrm{~kg}$ maka para nelayan menangkap ikan tuna di luar daerah rumpon.

Sistim penangkapan ikan tuna tongkol dan cakalang di PPS Bungus ditangkap menggunakan kapal rawai tuna, pukat cincin dan pancing tonda. Penggunaan pukat cincin tidak ramah lingkungan karena dapat menggangu keberlanjutan hidup populasi tuna dan biota yang dilindungi.

Hasil olahan tuna tidak semua dapat dimanfaatkan seperti sirip dan tulang ekor tuna terbuang. Dengan teknologi yang tepat guna sirip dan tulang ekor dapat dibuat tepung ikan untuk makanan ternak.

\section{UCAPAN TERIMAKASIH}

Data lapangan yang digunakan dalam penelitian ini berasal dari kegiatan penelitian yang dibiayai oleh DIPA Pusat Penelitian dan Pengembangan Sumberdaya Laut dan Pesisir, Balitbang-KKP tahun anggaran 2013 nomor MAK 2373.004.014.524111. Oleh karena itu penulis mengucapkan terima kasih kepada Dr. Budi Sulistiyo selaku Kapuslitbang SDLP dan tim kegiatan Ekonomi Biru. Terima kasih juga diucapkan untuk Ir. Ollyandes, S.PT dari Badan Koordinasi Penanaman Modal Sumatera Barat yang memberikan informasi tentang ikan-ikan yang bernilai ekonomis untuk diekspor, Khairul Amri dan Enjah dari Balai Penelitian Perikanan Laut Jakarta yang memberikan saran dan pengetahuan tentang tuna, tongkol dan cakalang. 


\section{DAFTAR PUSTAKA}

Anderson, LG., 1986. The Economic of Fisheries Management. The John Hopkins University Press, New York.

Anonim., 2004. Undang-undang No. 31 Tentang Perikanan. Jakarta.

Anonim., 2008. Peraturan Daerah Provinsi Sumatera Barat No. 13 Tahun 2008. Tentang Urusan Pemerintah yang Menjadikan Kewenangan Pemerintah Daerah Provinsi Sumatera Barat, Pemerintahan Daerah Provinsi Sumatera Barat, Padang.

Anonim., 2011. Keputusan Menteri Kelautan dan Perikanan No. 45. Tentang Estimasi Potensi Sumberdaya Ikan di Wilayah Pengelolaan Perikanan, Kementerian Kelautandn Perikanan, Jakarta.

Anonim., 2012 ${ }^{\mathrm{a}}$. Jumlah Produksi Ikan Menurut Jenis Ikan. Badan Pusat Statistik Kota Padang, Padang.

Anonim., 2012 ${ }^{\text {b }}$. Data Statistik Perikanan Tangkap Pelabuhan Perikanan Samudera (PPS) Bungus, 2012. Produksi Ikan Menurut Jenis Ikan di Pelabuhan Perikanan Samudera Bungus, 2007 - 2012, Direktorat Jenderal PerikananTangkap, Kementerian Kelautan dan Perikanan, Kota Padang, Padang.

Bourgeois, R., dan Jesus, F., 2004. Participatory Prospective Analysis: Exploring and Anticipating Challenges with Stakeholders. CAPSA Monograph No. 46. The United Nation, Bogor.

Coates, J., Durance, P., dan Godet, M., 2010. Strategic Foresight Issue: Introduction. Technol. Forecas. Soc. Change 77:1423-1425.
Damai, A.A., 2012. Sistem Perencanaan Tata Ruang Wilayah Pesisir: Studi Kasus Teluk Lampung Disertasi Sekolah Pasca Sarjana Institut Pertanian Bogor, Bogor.

Durance, P., dan Godet ,M., 2010. Scenario Building: Uses and Abuses. Technol. Forecas. Soc. Change 77:1488-1492.

Gjertsen, H., Hall, M., dan Squires, D., 2010. Conservation and Management of Transnational Tuna Fisheries, Wiley Blackwell, New Jersey.

Godet, M., dan Roubelat, F., 1996. Creating The Future: The Use and Misuse of Scenarios. Long Range Plann. 29(2):164-171.

Godet, M., 2010. Future memories. Technol. Forecas. Soc. Change 77:1457-1463.

Gunter, P., 2010. The Blue Economy. Published by Paradigm Publication, TAOS New Mexico.

Gray, T., dan Hatchard, J., 2008. A Complicated Relationship: Stakeholder Participation and the Ecosystems-based Approach to Fisheries Management. Mar. Pol. 32:158-168.

Human, B.A., dan Davies, A., 2010. Stakeholder Consultation During the Planning Phase of Scientific Programs. Mar. Pol. 34: 645-654.

Idris, Pi., dan Custer, J., 2012. Redisain Sistem Pendingin Ruang Palkah dan Air Laut Berbahan Fiber. Jurnal Ilmiah Mahasiswa 1(1):1401-1405.

Susilowati, I., 2006. Keselarasan dalam pemanfaatan dan Pengelolaan Sumberdaya Perikanan Bagi Manusia dan Lingkungan, dalam Pidato Pengukuhan Guru Besar Fakultas Ekonomi Universitas Diponegoro, Semarang. 